\title{
Design of a remote-operated underwater vehicle for visual inspection of research nuclear reactors
}

\author{
Wallacy Viana ${ }^{1}$, Amir Z. Mesquita ${ }^{2 *}$, Vitor F. de Almeida ${ }^{2}$, and Daniel Artur P. Palma ${ }^{3}$ \\ Unidade de Gestão de Engenharia, Arquitetura e Tecnologia (GEAT). Centro Universitário do Sul de Minas \\ (Unis/MG). Varginha, MG, Brazil ${ }^{1}$ \\ Núcleo de Irradiação Gama (Nuclig) Centro de Desenvolvimento da Tecnologia Nuclear (CDTN). Belo Horizonte, \\ MG, Brazil ${ }^{2}$ \\ Serviço de Análise de Segurança (Sease). Comissão Nacional de Energia Nuclear (Cnen). Rua Gal Severiano, 90, \\ Rio de Janeiro, RJ, Brazil ${ }^{3}$
}

Received: 16-November-2019; Revised: 19-December-2019; Accepted: 21-December-2019

(C)2019 Wallacy Viana et al. This is an open access article distributed under the Creative Commons Attribution (CC BY) License, which permits unrestricted use, distribution, and reproduction in any medium, provided the original work is properly cited.

\begin{abstract}
A remotely operated underwater vehicle (technically ROUV but commonly just ROV) is a tied underwater mobile device. This paper deals with the development of a remotely controlled submersible robot (ROV) which can be used for inspection or problem identification in submerged equipment and/or pipelines. The focus here is the visual inspection of submerged nuclear reactors during the fuel elements exchange, visualization of research reactor core, and spent fuel pool. Such an approach is necessary due to the fact that currently, robots are responsible for various tasks. Robots responsible for inspections, although not new, are highly specialized equipment. The development of a submersible robot that can adapt to various environments, and at low cost, would be a plus in this growing role. This intent was obtained by researching concepts such as density, buoyancy, ROV, direct current motors, control systems, terms such as radiation and radioactivity, and its interactions with electronic components. The parameters defined by the NBR-16244 standard were also observed, although it does not contain specific concepts for inspection in environments such as nuclear reactors. It is used as a basis for visual inspection in submerged environments. These concepts were allied to the use of programs such as SolidWorks ${ }^{\circledR}$ for hydrostatic modelling and project simulation. Simulations with different parameters were performed.
\end{abstract}

\section{Keywords}

Underwater, Visual inspection, ROV, PLC, Radiation, Nuclear reactor, Radiation.

\section{Introduction}

The present work presents the development of a submersible robot (ROV), which can be used for inspection or identification of problems in submerged equipment or pipes, focusing on visual inspection in pool-type nuclear research reactor, and irradiated fuel element reservoirs. It is also important to emphasize the contribution of work to the nuclear inspection and technology community. There is similar equipment already [1]. However, the ultimate goal of the project is the realization of the same with low cost. It is worth mentioning that due to the nature of the operating environment of the $\mathrm{ROV}$, it is convenient to focus on the radiological protection for gamma radiation.

*Author for correspondence

This work was supported by the Nuclear Technology Development Centre (CDTN), and Brazilian Nuclear Energy Commission (Cnen).
In nuclear research reactor has control rods whose main function is to capture neutrons, decelerating the reaction and effectively minimizing the fission and decay of the fuel elements. The most important component of a nuclear reactor is the fuel elements. They are the first protective barrier against the leakage of fission products. These elements require routine visual inspections [2].

Therefore, it is more convenient to use the ROV when the control rods are being used and the neutron emission is minimal, with the reactor off. Firstly, research was done on the ROV concept, its classifications and uses. The study of parameters for visual inspection of submerged installations was carried out, which were defined based on technical standard NBR-16244, which, although not specifically addressing nuclear reactors, presents pertinent concepts regarding the corrosion of 
submerged equipment [3]. A study of the adverse effects of radiation was also carried out. Added to this, there was the development of the prototype using a CAD (Computer Aided Design environment). It taking into consideration the proposals in relation to already existing models, hydrostatic evaluation of the model performed in a CAD environment, assembly of the model in real scale using available components, study of the principle of Archimedes applied to the model, in order to improve concepts such as stability and maneuverability culminating at the end, in a practical test of maneuverability.

\section{Materials and methods}

The following steps were used in the prototype development:

- Analysis of the ROV concept and applicability.

- The parameters used for visual inspection.

- Analysis of control systems and the applicability.

- Development of electronic control.

- Study of internal motor components.

- Study of buoyancy.

- Analysis of the radiation effects on components.

- Designing, and CAD simulations.

- Circuit assembly.

- Tests of equipment operation, without submission to ionizing radiation, to verify the equipment capacity.

\subsection{Concept of ROV}

An ROV (remotely operated vehicle), is a highly manoeuvrable unmanned vehicle operated by a person remotely. ROVs are essentially robots that allow the operator to stay in a comfortable environment while the ROV works in unhealthy environments. ROVs can range in size from small vehicles for simple observation to larger vehicles for complex jobs. They can count on several manipulators, TVs, cameras, tools and other equipment. It is also worth mentioning the presence of the power cable in most ROVs. This cable is responsible for conducting power to the ROV, as well as receiving signals from sensors and transmitting the images captured by the camera.

\subsection{Parameters and specifications of NBR 16244}

Another aspect of equal importance to be addressed is the basis for proper inspections. For this, the specifications provided by NBR 16244 are used. It details parameters for the inspection of underwater elements. It is worth noting that it does not provide any specific determination for the inspection of nuclear reactors, however, due to the use of watersubmerged equipment, it can be used as a reference parameter as it presents important concepts about underwater visual inspection in equipment and tubes [3].

\subsection{Direct and remote method of visual testing} The direct method is defined as: "Test performed with the naked eye with the aid of corrective lenses with direct observation of the surfaces to be inspected. A remote method is defined as: "Test performed with the aid of optical devices" Given these definitions, one can classify the project in question as an application model, a remote visual test method [2].

\subsection{Corrosion}

The NBR 16244 has one of the main points of corrosion, which is defined as: "chemical or electrochemical reaction that develops between materials. Usually a metal or a metal alloy, and the corrosive medium resulting in wear of the material" [3].

\subsection{Control systems}

Since the control systems that can be used for the construction of this particular ROV varied between the use of PLC and the use of the Arduino ${ }^{\circledR}$ platform. They are somewhat similar, it is necessary an explanation of the systems considered in this work, as well as a brief definition of inputs and outputs.

2.5.1 Physical computing

Physical computing is the use of electronic components for the realization of prototypes and machines. This involves the design of interactive objects that can communicate with humans or other machines through physical signals [4].

2.5.2Definition of inputs and outputs

For any computer to perform some task is necessary that it can receive data and demonstrate the results of their calculations. Devices that power data in controllers and computers are called input devices. Keyboards, mouse, keypads, and sensors can be cited as examples of input devices. The devices on which computers or controllers use to demonstrate the results are called output devices. Monitors, printers, motors and lights are examples of output devices [5]. 2.5.3Programmable logic controllers (PLC)

A Programmable Logic Controller (PLC) is an industrial computer that receives input signals from devices, performs evaluations of these inputs in relation to programming logic already stored in its memory then generates signals to the outputs in order to control peripheral devices. The PLCs use a programming logic called Ladder, which is similar to 
the line diagram used in control systems. The system is divided into lines (steps) which are composed of three basic sections: The signal, that of the action. The input module of the PLC receives the signals, which are used to execute the Ladder programming logic in relation to its values, make the decisions and finally the outputs are triggered according to the decisions made [6].

\subsection{The arduino ${ }^{\circledR}$ platform}

Arduino $^{\circledR}$ is a physical computing platform for creating interactive objects that can work alone or collaborate with software on a computer. The Arduino ${ }^{\circledR}$ is designed for artists, designers and others who need to incorporate physical computing into their designs, without having to have as much technical knowledge of PLCs or components of electrical panels [7].

2.6.1The integrated development environment

The integrated development environment is a program run on a computer, which allows the user to write programs to the Arduino ${ }^{\circledR}$ board in a simple language based on a language called processing. When the code is imported to the Arduino ${ }^{\circledR}$ board, the code is translated into programming language $\mathrm{C}$ and sent to the board, which executes it [5] [7].

\subsection{Motors}

DC motors are widely used in various applications, from toys to adjustable car seats automatically. These engines are inexpensive, easy to apply and are available in almost all sizes and formats. They are called so, because they use direct current as a form of power, unlike AC motors, which use alternating current for power [7]. All DC motors for simple operation with brushes are made with the same basic components: stator, rotor, brushes and a switch. The construction of a single brush DC motor is shown in Figure 1 [8].

\subsection{Floatability}

The buoyancy of a body is governed by the Archimedes Principle, which determines that the whole body immersed in a liquid suffers a force from the bottom up equal to the weight of the volume of displaced liquid. This happens because the displaced fluid has a relative density, the latter, which can be defined as: "Mass (M) and volume (V) are general properties of a material body. Absolute density (or simply density, d), or specific mass (p) of a homogeneous body is the ratio between its mass $\mathrm{M}$ and its volume V" [9] [10].

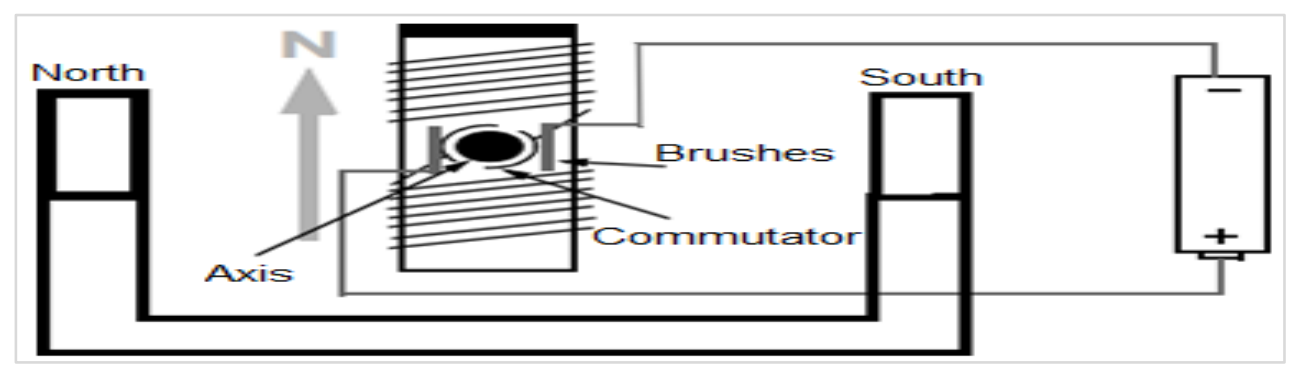

Figure 1 Schematic representation of a DC motor with brush

The weight of the displaced volume of the fluid then defines the above-mentioned upward force, also called thrust. When the thrust force of a body equals its force weight, the body is stabilized. This can be translated into the fact that bodies of equal densities tend to remain in equilibrium. Such displaced volume is also equal to the external volume of the ROV.

That said, the center of a body's fluctuation is the geometric center of the submerged structure and can also be calculated with a specific program like SolidWorks ${ }^{\circledR}[11]$.

\subsection{Effects of radiation in electronic components}

The electronic components can be affected in several ways by the radiations, being able to generate alterations in its operation, alteration of stored data and even transient or permanent damages in the semiconductor. This may cause malfunction or even component failure [12].

When integrated circuits are exposed to ionizing radiation over long periods of time, full-dose ionizing effects may occur. Its effects depend on the intensity and the exposure time of the affected circuit. These effects can be deviations in the voltage of the transistors, leakage of current, among others. Singular effects are caused by the interaction of high energy particles in the oxide, causing an ionization large enough to cause a current pulse with the potential to cause permanent damage to the component. Damage by displacement are damages 
caused by loss of energy in a non-ionizing way in the material, causing damage to the crystalline structure causing physical damage to the material. Such damages degrade the material in a gradual and irreversible way [13].

\subsection{Effects of polymer irradiation}

Some polymers, when irradiated, present changes in their physical properties. This is due to the effects induced by radiation in the polymer system. Considering these effects, the main effects are: reticulation and split in the main chain [13].

These are two distinct processes arising from the phenomenon of radiolysis. Radiolysis is a form of polymer degradation, and occurs by disruption of chemical bonds with high energy radiation. Such a process usually results in the crosslinking or cyclizing process of the polymer. The crosslinking process is more commonly observed than the socialization and causes an increase in the average molar mass, increasing the density of the polymer by increasing the polymer current [14].

2.11Improvements in electronic circuits submitted to ionizing radiation

Electronic circuits have some tolerance to radiation fields. However, for circuit submitted to higher doses, it is necessary to adopt measures to ensure its operation. Several methods can be used to improve the performance of systems using electronic circuits subjected to radiation. These are military class components which are subjected to tests and improvements aimed at guaranteeing the operation of the same subject to certain fields of ionizing radiation [12].

\subsection{Protection of electronic components}

It is possible to avoid the effects of radiation avoiding the use of sensitive components in the areas where the radiation is more aggressive. Therefore, the electronics should remain protected in an area where the radiation is lower. In order to reduce the number of components exposed to radiation, most of the intervention robots use umbilical cable, joining the robot and the control system where it houses the electronics of the equipment [12].

The shielding of sensitive components is a technique that consists of building a shield, where it is possible to protect the elements sensitive to radiation. In this way, the dose of such components will not exceed the recommended dose. The dose limit of damage to processors is $10 \mathrm{~Gy}$ to $500 \mathrm{~Gy}$ [12].

\subsection{Materials available}

The present project, is proposed to manufacture the prototype with low cost, making necessary the use of cheaper materials, however without prejudice to the quality of the study. It is important to note that some of the parts involved were obtained from discarded materials. The main materials available for manufacturing the robot were:

- Mini Water Pumps;

- Rigid PVC pipe;

- Nylon;

- Cables and wires;

- Endoscopic camera;

- Arduino ${ }^{\circledR}$ Mega 2560;

- Buttons -Touch switch.

\section{Results}

First, all parts were individually drawn using the Solidworks® program (Figure 2). All measurements were taken precisely with the use of a calliper, and subsequently measurements of the weight of each of the parts were carried out. Subsequently the pieces were machined by a CNC machine and fitted.

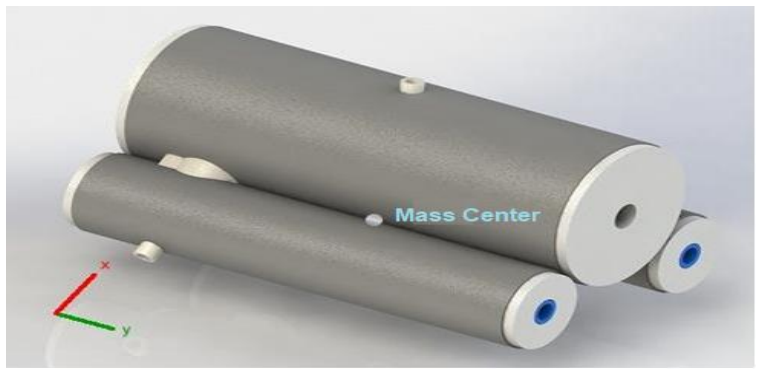

Figure 2 Concept, made with solidworks ${ }^{\circledR}$

\subsection{Pressure resistance simulations}

Pressure tests were performed simulating a calculated pressure for a column of water of at least $6 \mathrm{~m}$ on the tube. The characteristics of rigid PVC were first defined by the SolidWorks ${ }^{\circledR}$ program, and then the pressure resistance tests were performed. On the first test, only the pressure in the water column was considered. Using a pressure equivalent to $6 \mathrm{~m}$ of water column, the average depth of the location of the IPR-R1 Triga nuclear research reactor core being converted to pascal is $58860 \mathrm{~Pa}$. The maximum tension in the pipe is approximately $550,000 \mathrm{~Pa}$ or $0.5 \mathrm{MPa}$. In the second test the pressure defined above was added to the atmospheric pressure of $101325 \mathrm{~Pa}$, resulting in a pressure of $160,185 \mathrm{~Pa}$. The maximum tension in the tube is approximately $1,500,000 \mathrm{~Pa}$ or $1.5 \mathrm{MPa}$. The yield stress for rigid $\mathrm{PVC}$ is $50 \mathrm{MPa}$. Thus, it is possible to conclude that the pipe presents adequate resistance to the pressure 
of the water column offered by the Triga Mark I reactor at CDTN/Cnen [15], [2]. In fact, performing more tests, it was found that the critical pipe failure occurs at a pressure of approximately $540000 \mathrm{~Pa}$, which, in terms of depth, is equivalent to a depth of approximately $55 \mathrm{~m}$.

3.2Final assembly and idealization of the electronic circuit

Using the concept of electronic components reduction mentioned above, the control center containing the Arduino ${ }^{\circledR}$ board would be isolated from the ROV being connected to it by network cables. For the assembly of the control electronics, a wooden box with dimensions $450 \mathrm{~mm}$ x $350 \mathrm{~mm}$ x $130 \mathrm{~mm}$ was used. Other components such as LEDs, resistors and buttons were used for general circuit assembly. The circuit has been designed in order to drive the motors independently of one another. For this, a simple push button scheme was used.

The physical structure of command containing the buttons is in the control of board. The equipment consists of a smaller wooden box with dimensions $150 \mathrm{~mm} \times 150 \mathrm{~mm} \times 50 \mathrm{~mm}$ which contains the buttons that are pressed in order to perform the control of the motors. The first version of the prototype also has an LCD to show the local temperature using a thermometer coupled to the ROV housing. However, the LCD and thermometer are inactive in the final version. A representation schematic of the connection of the electronic components can be seen in Figure 3.

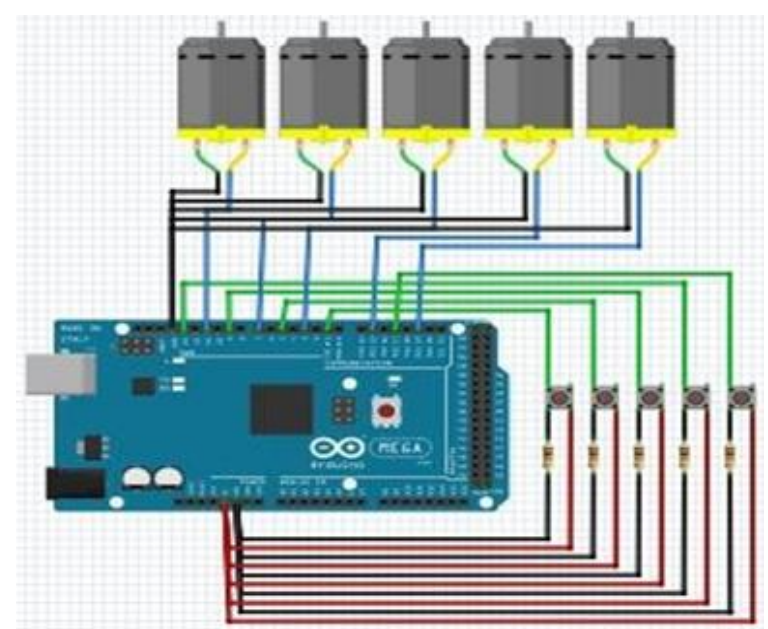

Figure 3 Schematic representation of the connection of components

The system consists of the direct drive of a water pump at the press of a button. The camera is attached 24 to the front of the product. Although it already has leds internal to the protective glass of your lens were added two leds of high brightness in the part of the front of the ROV being these holes also specified for machining the part. It is important to highlight the presence of the camera's USB input, which is kept independent of network cables coupled to the ROV and is connected directly to the command computer The circuit has been designed in order to drive the motors independently of one another. For this, a simple push button scheme was used. The system consists of the direct drive of a water pump at the press of a button. The camera is attached to the front of the product. Although it already has leds internal to the protective glass of your lens were added two leds of high brightness in the part of the front of the ROV being these holes also specified for machining the part. It is important to highlight the presence of the camera's USB input, which is kept independent of network cables coupled to the ROV and is connected directly to the command computer (Figure 4).

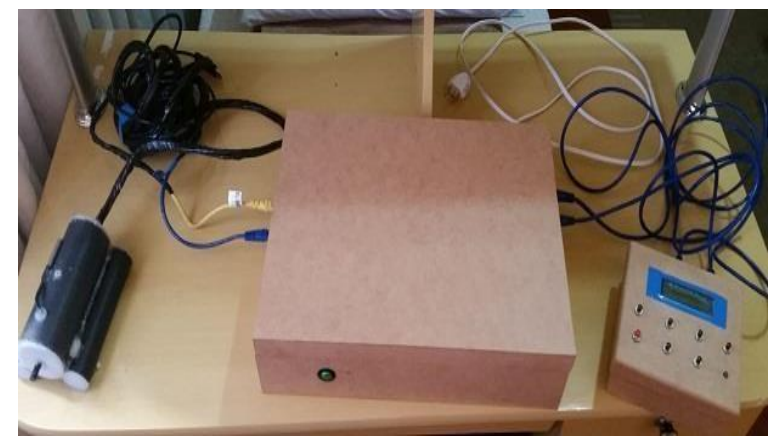

Figure 4 Completed montage of the ROV system

\subsection{Programming}

Using the LDmicro program a simple ladder programming consisting only of simple inputs and outputs considering the Arduino ${ }^{\circledR}$ board and the physical components, has been adapted for use on the Arduino ${ }^{\circledR}$ platform.

\subsection{Tests}

A basic control test was performed with the submerged ROV. One of the main problems observed was that the rigidity of the umbilical cord made the ROV difficult to in future versions. Cables should be replaced with cables that facilitate $\mathrm{ROV}$ maneuverability [16]. With the ROV submerged, a test was performed on the lighting coming from the camera and its image focus. A brief test of maneuverability was also conducted. The results are presented in Figure 5. 


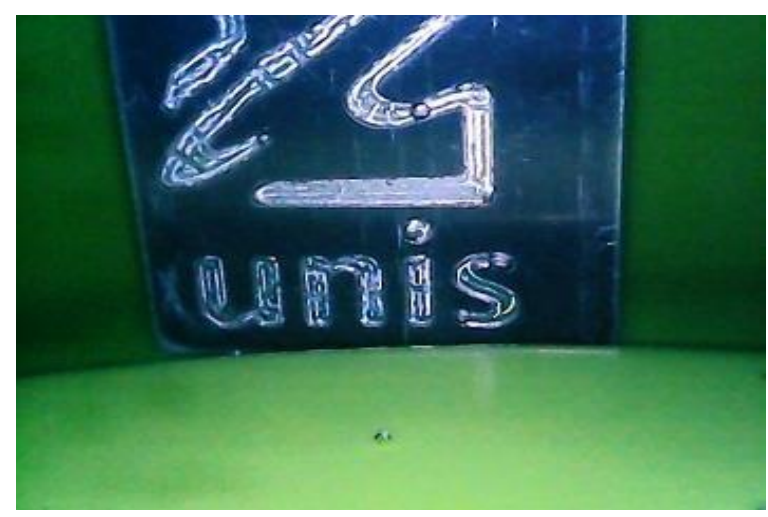

Figure 5 Resulting image from the test

\section{Conclusion}

With the advent of this work it can be concluded that the development of a remotely controlled submersible robot for visual inspection of nuclear reactors is possible. It is worth remembering that some key factors were not considered in this work. For example, the radioactive shielding power of the water and the neutron field conditions of the Triga nuclear reactor. However, considering the scope of previous calculations allied to the use of higher quality materials, it is plausible to consider that the ROV has a satisfactory operation during a visual inspection of the reactor. Another factor that can be explored in future works is the use of a hoisting system, whose main objective is to avoid the direct contact of the user with the reactor water, performing lifting of the ROV at the end of each inspection or if there is any malfunction of any of the components.

The prototype developed in this work, because it does not present an effective camera shield, or any other method of improving its protection, presents viability directly related to the intensity of the radiation field emitted from the reactor core. It can be used, provided that more rigorous research is carried out on the effective radiation indices in the work area of the equipment, performing an effective inspection of the reactor components.

It can be observed that due to the long period of time that nuclear reactors remain in operation, it is of great importance to carry out inspections that may detect damage to the external surfaces of fuels. These elements can result in faults, which may lead to the decommissioning of the reactor by the regulatory agencies. To date, there is still a gap to be filled in the field referring to submersible ROVs applied to the nuclear area. These equipment's still have prohibitive acquisition costs for most of the area's 25 research institutes. It is important to emphasize that concepts relevant to future versions of the ROV were developed in this work, as well as concepts relevant to its buoyancy and the specific levels of radiation related to the reactor.

\section{Acknowledgment}

This research project was supported by the following Brazilian institutions: Nuclear Technology Development Centre (CDTN), Brazilian Nuclear Energy Commission (Cnen), Research Support Foundation of the State of Minas Gerais (Fapemig), and Brazilian Council for Scientific and Technological Development (CNPq).

\section{Conflicts of interest}

The authors have no conflicts of interest to declare.

\section{References}

[1] Diez-Garias FJ, Maia MM, inventors; Rutgers state university of new jersey, assignee. unmanned air and underwater vehicle. United States patent US 10,315,762. 2019.

[2] Mesquita AZ, Salles BM, Luciano MR. Design of a visual system to monitoring thermal power in pooltype nuclear research reactor. International Journal of Advanced Engineering Research and Science. 2019.

[3] Viana W. ROV INSPECTION: Visual inspection equipment in nuclear reactors. 2018.

[4] Azis FA, Aras MS, Rashid MZ, Othman MN, Abdullah SS. Problem identification for underwater remotely operated vehicle (ROV): a case study. Procedia Engineering. 2012; 41:554-60.

[5] Banzi M, Shiloh M. Getting started with Arduino: the open source electronics prototyping platform. Maker Media, Inc.; 2014.

[6] Doyle B. C\# Programming: from problem analysis to program design. Cengage Learning; 2013.

[7] Kamel K, Kamel E. Programmable logic controllers: Industrial control. McGraw Hill Professional; 2013.

[8] Yedamale P. Brushless DC (BLDC) motor fundamentals. Microchip Technology Inc. 2003; 20:315.

[9] Gamazo-Real JC, Vázquez-Sánchez E, Gómez-Gil J. Position and speed control of brushless DC motors using sensorless techniques and application trends. sensors. 2010; 10(7):6901-47.

[10] http://www.scielo.br/scielo.php?script=sci_arttext\&pi $\mathrm{d}=\mathrm{S} 1806-11172013000100024$. Accessed 21 October 2019.

[11] http://www.pee.ufrj.br/index.php/pt/producaoacademica/dissertacoes-de-mestrado/20071/2007062501-2007062501/file. Accessed 13 March 2018.

[12] Martins DE. Braço manipulador replicador de movimentos de similaridade anatômico aplicada a atividades em campos de radiação ionizante. Master Dissertation. Programa de Programa de Pós-graduação em Ciência e Tecnologia das Radiações, Minerais e 
Materiais, Centro de Desenvolvimento da Tecnologia Nuclear. Belo Horizonte. 2018.

[13] Lima IS, Araújo ES. Efeitos da radiação gama na estrutura e nas propriedades do poliestireno (Doctoral dissertation, Tese de Mestrado, Universidade Federal de Pernambuco, Brasil).

[14] From Paoli MA. Polymer degradation and stabilization.2009.

[15] Braskem SA. Desenvolvimento de PVC reforçado com fibras de vidro longas para fabricação de produtos moldados. Polímeros. 2011; 21(5):369-75.

[16] Dudykevych V, Oleksandr B. Tasks statement for modern automatic control theory of underwater complexes with flexible tethers. Eureka: Physics and Engineering. 2016; 30(5):25-36.

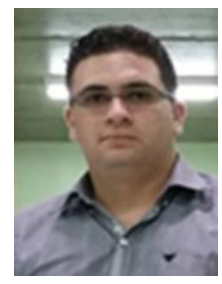

Wallacy Viana is graduated in Mechanical Engineering from the University Center of Southern Minas Gerais (Unis-MG) with emphasis on welding processes, mechanical and metallographic essays, and textual production focused on the academic area. Engineer responsible for MRW Máquinas Ltda located in Três Corações (MG/Brazil), which operates in the field of industrial automation, and production of machines for cold pressure welding. Carries out projects in the areas of Automation, Energy and Automation Focused on Nuclear Engineering with an Emphasis on Visual Inspections.

Email: wallacy.viana@gmail.com

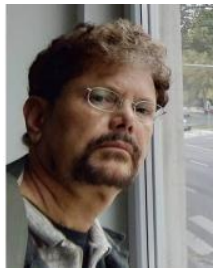

Amir Zacarias Mesquita is Doctor of Science in Chemical Engineering, Unicamp, Brazil (2005), Master of Science and Nuclear Technologies UFMG/Brazil (1981), graduated in Electrical Engineering -UFMG/Brazil (1978). He is researcher at the Brazilian Nuclear Energy Commission (Cnen). Nuclear Reactor Senior Operator, and Post-Graduate Professor. $\mathrm{He}$ is involved in research in Nuclear Engineering with an emphasis on Reactor Technology, Thermo-Fluid Dynamics, Gamma Irradiation, and Reactor Physics achievements, etc.

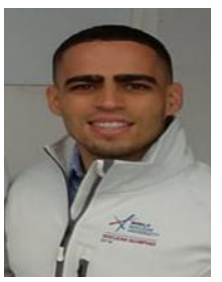

Vitor Fernandes de Almeida performs his masters in Radiation, Minerals and Materials Science and Technology from the Center for Nuclear Technology Development (CDTN). Graduated in Chemical Engineering from UNA University Center (2016), awarded as a silver medal student, MBA in Strategic

Project Management.

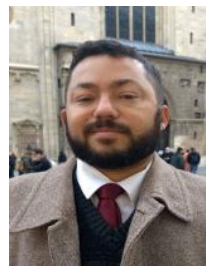

Daniel Artur Pinheiro Palma is Doctor of Science in Nuclear Engineering from Coppe/UFRJ (2009). Master in Physics from the UFRJ (2004). Bachelor of Economic Sciences from the University of Northern Paraná (2018). Graduated in Physics from the UFRJ (2002). He is a Senior Technologist of the Cnen/Brazil, where he holds the position of Head of Safety Analysis Service and General Coordinator of Reactors and Fuel Cycle. He is a member of the Nuclear Reactor Operators Licensing Board. 